This item was submitted to Loughborough's Research Repository by the author.

Items in Figshare are protected by copyright, with all rights reserved, unless otherwise indicated.

\title{
Meeting the library needs of distance learners without additional funding
}

PLEASE CITE THE PUBLISHED VERSION

PUBLISHER

Emerald Group Publishing Limited / @ Elizabeth Gadd

VERSION

AM (Accepted Manuscript)

LICENCE

CC BY-NC-ND 4.0

REPOSITORY RECORD

Gadd, Elizabeth A.. 2019. "Meeting the Library Needs of Distance Learners Without Additional Funding". figshare. https://hdl.handle.net/2134/4305. 
This item was submitted to Loughborough's Institutional Repository (https://dspace.lboro.ac.uk/) by the author and is made available under the following Creative Commons Licence conditions.

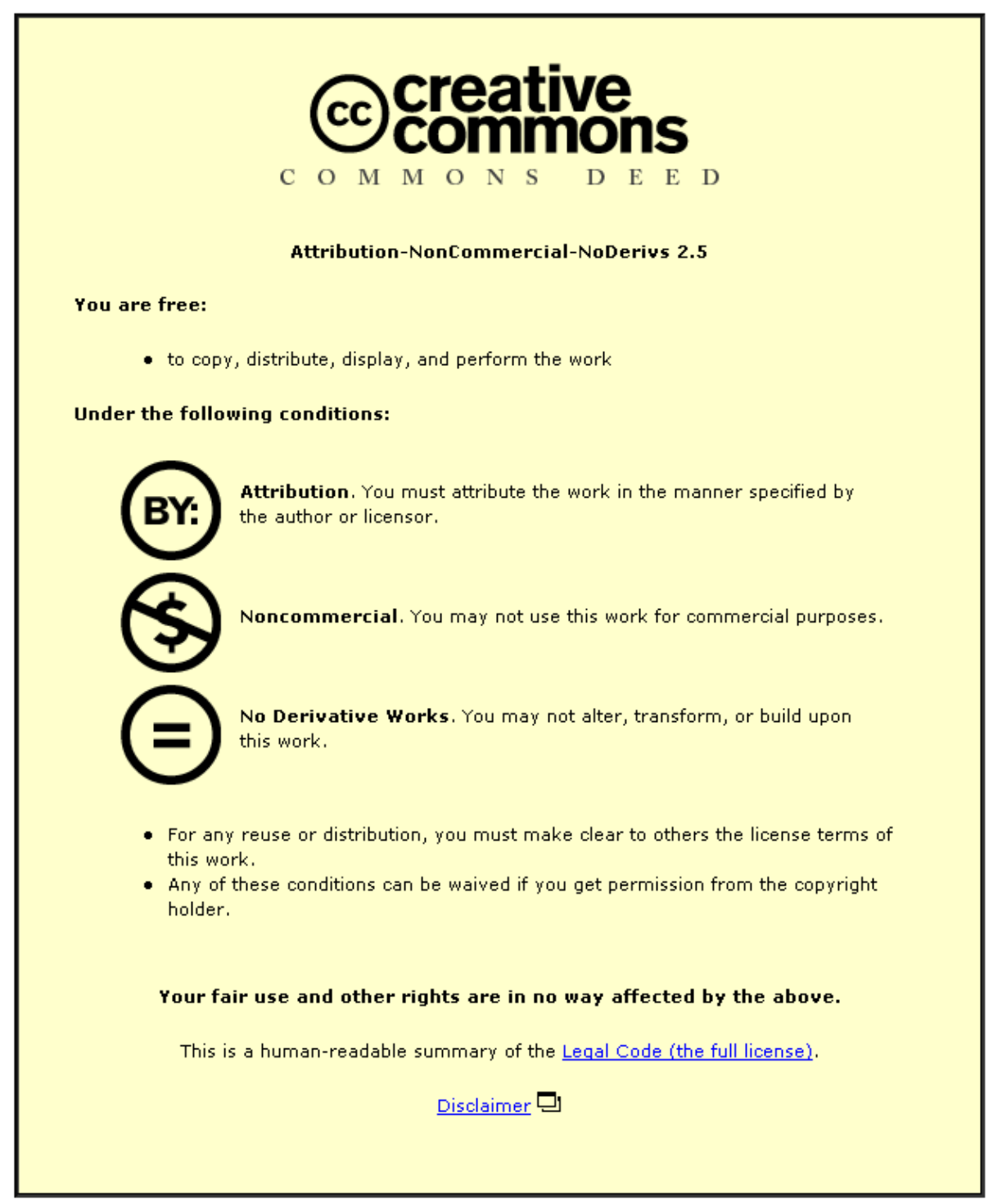

For the full text of this licence, please go to: http://creativecommons.org/licenses/by-nc-nd/2.5/ 


\title{
Meeting the library needs of distance learners without additional funding
}

\section{Elizabeth Gadd}

\section{Acknowledgements}

The author acknowledges the hard work put in by members of the Loughborough University Library Distance Learning Working Group, Jane Bramley, Ginny Franklin, Heather Jennings and Ruth Stubbings, on which this article is based.

\begin{abstract}
States the problem of incorporating distance learning (DL) library services without additional funding. Describes the work of a Distance Learning Working Group at Loughborough University Library. Activities included an analysis of the characteristics of DL courses and students at Loughborough; a comparison of library services to on- and off-campus students; a survey of DL students and academics; and a benchmarking exercise comparing DL library services at Loughborough with those at local and peer group institutions. Key outcomes of the research are presented.
\end{abstract} Details the suggested methods of funding the Working Group's recommendations.

\section{Introduction}

Around the country there are many examples of good practice in providing library services to distance learning (DL) students. Sheffield Hallam's Distance Learner Support Service (2001), Leicester University’s Distance Learning Unit (2001), University of Surrey's DILIS (2001) are just three cases in point. However, many of the services that are held up as exemplars to the Library community are fortunate enough to receive additional funds to achieve their high standards, usually by virtue of the large number of existing or expected DL students at that organisation. How should those HEIs cope that have small "pockets" of distance learners, all on different courses with different library and information needs, and that are unlikely to receive top-sliced funding with which to provide a comprehensive DL service? This article aims to address this issue based on the experiences at Loughborough University.

\section{Working Group}

In February 2001, Loughborough University Library established a Distance Learning Working Group consisting of five members of library staff. Its aim was, "noting the University strategic objectives to widen participation and to increase the number of programmes delivered by distance learning, [to] tailor Library services to the needs of such groups, as resources permit." In response to the growing demand for flexible services the Library had already made a number of provisions that would benefit parttime (PT) and DL students. These included a set of web pages, membership of UK Libraries Plus (2001), longer loan periods, a photocopying service and bookable PCs. However it was felt that a comprehensive evaluation of our services informed by a survey of current and future DL provision at Loughborough was necessary. The terms of reference of the Group were:

- To describe current distance learning provision at Loughborough.

- To investigate any plans in academic departments to increase (or decrease) that provision.

- To describe the Library's current services in relation to distance learners and their needs. 
- To benchmark the University Library's support for distance learners against other libraries in the region, and against a selection of libraries in similar institutions elsewhere.

- To make recommendations for future Library policy and practice.

For the purposes of the Group, the definition of a Distance Learner was "any student who lives so far away from Loughborough that it would be difficult or impossible for them to derive the same benefit from existing Library services as other students; and those whose personal circumstances may prevent them from attending at times which make it possible to benefit from those services.” The Group had five months in which to report.

\section{Distance learning at Loughborough}

The Group's first task was to build up a profile of the DL activity at Loughborough. There is currently no central focus for Distance Learning at Loughborough University, and no official figures on the number of DL courses or students. We were later to discover that this is not an uncommon situation in HEIs. The Group was fortunate therefore to be able to build upon the work of the University Distance Learning Project Officer who had already done some data gathering. This information was supplemented by the results of a questionnaire survey performed by the Group on academic staff in charge of DL courses.

In 2000/01 there were 12,022 students at Loughborough University. Fourteen per cent of these $(1,742)$ studied part time. The Group's research indicated that there were currently at least 1,000 DL students spread across 21 courses offered by 16 (of the 24) departments at Loughborough. The mean number of students on any DL course was 66. (The range was from 10-250 students). It was immediately apparent that we were not dealing with a small number of large DL courses with a high profile on campus, but a large number of small courses, many of which were offered by small research groups with an international reputation and a niche market. As a result the majority of courses (eighteen - 86\%) were postgraduate courses, and mainly part time.

Exceptions to the rule came in the form of three undergraduate courses and some fulltime courses. Only one of the undergraduate courses was offered entirely by DL, the other two contained a small number of modules that could be studied by DL.

Courses were offered by a variety of different methods ranging from entirely paperbased to purely web-based, and a variety of hybrids in-between including some use of CD-ROM and video. Perhaps not surprisingly, the learning resources provided by the courses to their students also varied. These are listed on the graph below. 


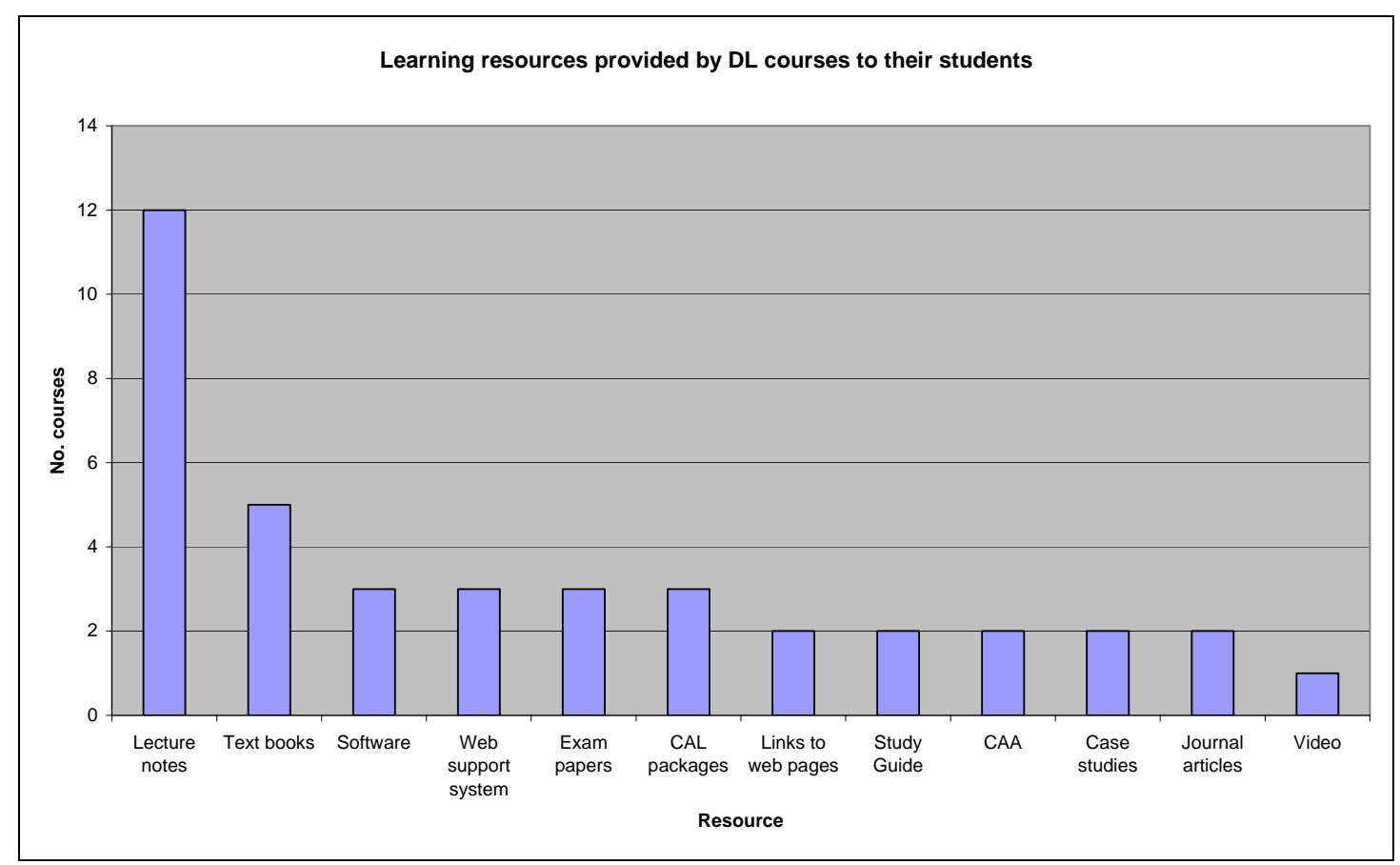

Figure 1

It became clear that every DL course at Loughborough offered their students a slightly different learning experience and would therefore have different expectations of the library. Some courses went to great lengths to compile copyright-cleared coursepacks or CD-ROMs of material to make their course library-independent. Others leaned heavily on library provision.

A DL course's delivery method did not necessarily influence the likelihood of its students visiting the campus. Eighteen courses (86\%) expected their DL students to visit campus at some point. Eleven (52\%) said a visit was essential, seven (33\%) said it was likely, and only three said it was not required. Of these three, one course was delivered by paper only, one by web-only, and the other by paper and video. It was interesting however, that the vast majority of DL students were likely to visit campus. In fact the average number of days a DL student would spend on campus over one year was 6.5 days. Two-thirds of DL students got the opportunity to attend a residential course of between 1.5 and 7 days.

On the face of it, this was good news for the library. The more likely a student was to spend time on campus, the more likely they were to visit the library. A visit to the library would at least give the student a mental model of the facilities on offer and of staff willingness to help. However, 6.5 days a year on campus is not many, and packed agendas may preclude a library visit. Indeed, one academic wrote:

"Our students attend one week residential modules which start at 9am and finish at $6 \mathrm{pm}$. Unfortunately this means they are not able to visit the library if the module runs outside term time.”

To an academic, such experiences may make library services appear incompatible with the needs of DL students. 
In terms of geographical location more diversity amongst our DL students was uncovered. Sixteen courses indicated where their students were located. Only onequarter of these said all their students were based in the UK. The others had students in a variety of locations including Europe, the United States, Canada, the Far East, Middle East, India and Australia.

\begin{tabular}{|l|c|}
\hline $\begin{array}{l}\text { Location of DL } \\
\text { students }\end{array}$ & No. courses \\
\hline UK only & 4 \\
\hline UK \& RoW & 3 \\
\hline Europe \& RoW & 1 \\
\hline UK, Europe \& RoW & 8 \\
\hline
\end{tabular}

Table 1

Again, because academics' perception of the library is that of a place that meets the needs of Loughborough-based students they may not consider its relevance to offcampus students. Indeed, students themselves may preclude themselves on the basis of their geographical location.

The final, and perhaps most important, aspect of the DL picture at Loughborough was whether the number of such courses would increase or decrease in the future. The University's strategic objective was to increase the number of courses offered by DL, but did academic staff share the same vision? Our survey showed that $86 \%$ of responding academics felt that DL would increase at Loughborough University. This thought was echoed by the University's Distance Learning Project Officer who felt that DL or open and flexible learning would increase steadily at Loughborough.

This overview showed us that whilst strategically DL was likely to increase at Loughborough, currently the relatively significant number of geographically diverse distance learners were spread across a wide range of different courses with different library expectations. The lack of a uniform student profile meant that it would be challenging meeting their needs. The lack of a uniform approach or centralised coordination to DL at Loughborough meant that the likelihood of top-sliced institutionwide funding for a set of DL library services was slim.

\section{Comparison exercise}

Once we had a full picture of the current DL provision at Loughborough, the Group's attention turned to meeting the needs of this diverse population. The starting point was the library services already offered to distance learners. The two key questions were 1) were they equivalent to the services offered to on-campus students, and 2) were they actually meeting the needs of DL students. A recurring recommendation in the literature is to ensure that services to DL students are equivalent to those oncampus (e.g. Cervone \& Brown, 2001, Gibson et al, 1999). The Group took this tenet seriously and produced a comprehensive list of the library services and facilities that on-campus students enjoy. The list fell under three main headings: 1) access to library materials; 2) physical facilities; and 3) help, advice and training. This was compared to a list of equivalent services for DL students, along with any statistics on take-up of those services. Where no equivalent service was available, ideas for new services to "fill the gap" were suggested. 
The resulting list of potential service improvements ran to twenty-six items. Some general conclusions were also drawn from this exercise. Firstly, the take-up of some of our existing services to distance learners was very low. A greater marketing effort would therefore be necessary in future. Also, it was not always easy to measure the use of some services. It would help any future assessment of DL services if their take-up were monitored carefully.

\section{Meeting needs}

Of course providing truly equivalent services to on- and off-campus students may not always be the best course of action for either group. DL students may have different library needs that need to be addressed in new ways. At the same time, new services introduced for DL students should not disenfranchise on-campus students. The Group's next task was therefore to discover what the specific library needs of DL students and academics were. A survey of 400 DL students was undertaken by the Library in 1999. The resulting data was revisited and re-analysed for the purposes of the Group. Academics' views were sought via the email questionnaire survey mentioned above.

\section{Views of students}

The purpose of the 1999 survey was to assess DL students' satisfaction levels with current library services, as well as to glean suggestions for additional services. Just over 120 responses were received - a response rate of 30\%. The responses indicated that " $70 \%$ of respondents were satisfied with borrowing periods, with a greater number (76.8\%) satisfied with the existing arrangements for loan renewal.”

However, the opportunity to give free-text comments sent a number of clear messages to the library. The first highlighted the desire for longer opening hours. Thirty-eight respondents named specific additional opening times that would be of benefit to them. Thirty-two of these (86\%) requested additional vacation opening hours (evenings and/or weekends). The second message was that short (24 hours) and one-week loan books were virtually useless to DL students. The third message came indirectly through the number of students requesting services that the Library already offered. For example, three students wanted books-by-post. This again highlighted the need for improved marketing of DL library services, something identified by Wolpert (1998).

\section{Views of academics}

In addition to the information academics' provided about their courses to inform the "big picture" at Loughborough, they were also asked to rate some existing DL Library services and suggest additional services. The services they were asked to rate included books by post; photocopying service; services bookable in advance (such as PCs, and study carrels); and information skills training (IST). The ratings they could apply were "essential”, "useful”, "may be useful”, and "unnecessary". Fourteen of the 21 DL academics responded.

Top of the list came IST. Fifty per cent (7) of respondents regarded IST as essential and only two respondents thought such training was unnecessary. Books-by-post were also highly valued. Fifty per cent (7) rated this service as either essential or useful. A further five respondents thought it may be useful. Eight respondents thought photocopied articles may be useful. Only one thought this was essential and 
three rated it unnecessary. Services bookable in advance received the lowest ratings with the majority of respondents (6) considering it unnecessary for their students.

In terms of additional services they would like to see the library develop for Distance Learners, seventeen different suggestions were made. Nine would represent completely new services, four would be extensions of existing services, and four were services the library already provided. This latter category emphasises yet again the need for a renewed marketing effort for DL Library services.

\section{Benchmarking}

The final task of the Group was to see how our services compared to those offered by other University Libraries to their distance learners. A questionnaire was designed and was sent out by email to two groups of University Libraries: a regional group and a peer group. The main subjects covered were:

- The number of DLs;

- The nature of Library staff providing services to DLs;

- $\quad$ Physical facilities offered (opening hours etc);

- Help and training provided;

- Library materials (books-by-post, literature searches etc);

- Other services provided.

Sixteen libraries responded to the survey.

\section{Numbers of distance learners}

Many Universities did not know the exact number of Distance Learning students they had, or the figures depended on their definition of a Distance Learner. At Derby for example, there are approximately 250 students on "pure” DL courses, but many more on part-time courses that offered the occasional DL module. Overall the figures seemed to range from a handful of DL students to 5,000-6,000 at Leicester University.

The difficulty in determining DL numbers had a knock-on effect on determining the number of DL students that used Library services. Derby estimated that 25-30\% of DL students made use of dedicated postal loan and photocopy services. DMU estimated that $80 \%$ appeared to be "using the extensive list of Library databases", with a smaller percentage using other services. 4,000 of Leicester's DL students have registered with the Library, but not all of them go on to use the services. Oxford Brookes had recently performed a survey of DL students and discovered that " $88 \%$ of respondents had used [their] postal loan service at some point.” At Surrey approximately 150 of their 1500 plus distance learners use their "DiLIS" service.

It appears that the unique identification of DL students on University and Library administrative databases is something from which many HEIs would benefit. Indeed it is imperative to quantify the market for which you are developing specialised services. Such information would also allow the targeted marketing of those services, and would save individual distance learners from having to prove their identity in order to benefit from them. 


\section{Dedicated staff}

Eight of the sixteen libraries dedicated staff time to providing services to distance learners. Dedicated staff ranged from 0.3 FTE to five FTEs. It was difficult to draw any conclusions about the ratio of staff to DL students because of the patchy provision of student numbers. However, those Libraries with dedicated DL staff that also supplied student numbers revealed that they ranged from 250 to 6,000. The literature reports that in order "to meet the needs of 1,000 distance learning Education students [at Leicester University], the [distance learning library] service employs two full time equivalent assistants (who spend... about two-thirds of their time on DL business)" (Raven, 1999).

Five Libraries indicated how the dedicated posts were funded. Three services were funded through the normal Library staffing budget, one was funded through a mixture of staffing budget and project funding, and the other was funded as a result of the Library receiving a percentage of the course fees.

Libraries that did not have dedicated DL support staff utilised subject librarians, senior library assistants, and circulation staff in dealing with DLs. One Library had a staff member dedicated to part-time staff, and as such, dealt with the majority of DLs too.

\section{Physical facilities}

In terms of providing physical access to library facilities, ten of the fourteen Libraries were currently members of UK Libraries Plus, or were just about to join. Only four Libraries stated that they provided additional opening hours themselves for DL students. However many Libraries were already offering extensive opening hours for their on-campus students that would benefit distance learners. No Libraries provided bookable PCs or laptop computers to their students. However, ten Libraries provided some form of bookable study rooms whether individual carrels or group study rooms.

\section{Help and training}

With regards to help and training, ten libraries provided some form of electronic enquiry service. In some cases this was a general service that any University member could use. In others it was a service dedicated to Distance Learners. In the latter case, the service was not always limited to enquiries, but could also be used to request postal loans and other such services. Twelve Libraries gave information skills training to DL students while on campus - if they were informed about the students beforehand. A few Libraries (six) had developed interactive, web-based information skills training packages, or were considering doing so. The provision of publications and/or web pages explaining library services for distance learners was common. Only one Library did not provide anything of this nature.

\section{Library materials}

A high proportion of respondents (10) provided a postal books service for distance learners. Five libraries made no charge, or just required DLs to pay the return postage. Four libraries charged a fee of $£ 2.50$ or less. Special loan periods for DL students were offered by three libraries. Five libraries were more lenient to distance learners either officially or unofficially ("we treat with sympathy" and "standard rules applied flexibly” were two comments). Three libraries offered a grace period in 
which fines were not applied. Another froze fines after they reached a certain level. At one library loans issued to DLs could not be recalled. Telephone bookings and renewals were also offered.

Nine libraries offered a photocopying service to their DLs. There were as many different charging mechanisms as there were Libraries. The literature shows that some services set target turnaround times for their photocopied article and postal books service (Linden, 2000). At Sheffield Hallam University the turnaround time is 3 days (Bye, 1999).

Twelve of the fourteen responding Libraries stated that they favoured databases that offered remote access even though this may not have been an explicit policy, or one with DL students primarily in mind. Obviously remote access to databases benefits more than just distance learners. To ensure equality of access to databases, fifty-per cent of responding libraries provided literature searches for their distance learners. Only one Library charged a fee ( $£ 5$ per search). In four cases Subject Librarians performed the searches. One Library stated that literature searches would only be performed on sources not available remotely. Another stated that this would only be performed where licences permitted.

No Libraries provided dedicated collections of books for DL students, although two provided them for part time students. One library used to provide such a collection but found it was underused. Another commented that Manchester University had recently disbanded their DL collection for the same reason.

\section{Funding the recommendations}

The Working Group made 49 recommendations to the Library Management Group for the improvement of services to DL students. The question was how were they to be funded? The funding of DL library services is a common theme in the literature (e.g. Burch, 1999). The Association of College and Research Libraries' Guidelines (1998) for distance learning library services states that:

"Traditional on-campus library services themselves cannot be stretched to meet the library needs of distance learning students... who face distinct and different challenges involving library access and information delivery...The originating institution is responsible, through its chief administrative officers and governance organizations, for funding and appropriately meeting the information needs of its distance learning programs.”

This is clearly the ideal way forward for the funding of DL library services. Indeed the SCONUL Task Force on Access for Distance Learners (2001) endorses this view. However, top-sliced funding such as this will not be the reality for a number of organisations, as the Task Force recognised. They suggested that there were four ways in which DL services might be funded:

- "the student pays directly for each transacation (e.g. postal loan)

- the department transfers funds to the library to meet the costs of the service

- the library meets all costs from within its own budget

- the institution provides funds for an additional premium library service.” 
At Loughborough it was felt our recommendations fell into three main funding categories:

- Free services (to be added at little extra cost - usually staff time)

- Added value services (to be provided on pay-per-use basis)

- Investment services (could only be provided with considerable extra resources)

\section{"Free" services}

No service is free to provide. However, it was felt that a good proportion of our recommendations would benefit our DL students at little cost to the organisation. These improvements fell under four main headings: strategic changes; policy changes; procedural changes; and web improvements.

\section{Strategic changes}

This first set of recommendations encouraged changes in the Library's strategic approach to DL students. The primary recommendation in this category was to assign someone the responsibility of co-ordinating services to distance learners. There was no direct cost to this, but it would ensure that DL students' needs were represented at a strategic level in future. It was also recommended that services to distance learners were marketed more actively both to students and academics. As part of this process Academic Librarians were encourage to get involved with the planning of DL courses in their departments. The Library was also recommended to actively pursue services that would benefit distance learners such as electronic books, the digitisation of exam papers, "virtual librarian" projects such as OPAL (Online Personal Academic Librarian) (2001), and the provision of tables of contents of books and journals on the Library OPAC. A couple of these initiatives were already on the Library's strategic agenda because of their relevance to on-campus students. However their relevance to distance learners would give them some priority.

\section{Policy changes}

The Library was encouraged to change its policy on a number of matters. The key recommendation here was that loan periods for books in all loan categories were extended for DL students. Of course, this is where a Library's definition of a DL student becomes important. In principle it's all very well making your definition broad and inclusive. However, when it comes to offering different levels of service to different user groups, the definition suddenly needs to become succinct and specific. Libraries that have an institution-wide definition of a DL are saved the trouble of drawing their own lines.

A couple of other circulation policy changes were recommended including stopping fines on overdue recalled books if the DL telephones and returns the book within one week. Target turnaround times for the photocopying and postal book services were also suggested. Finally, it was agreed that sources allowing remote access should always be preferred over campus-only products unless the interface and/or data is considerably inferior in the remote access product.

\section{Procedural changes}

It was decided that for little extra staff time a number of procedural changes could be implemented to improve our service to DL students. For example our new Library Management System, Aleph, could be set up to send email reminders to DL students 
that their books were due for renewal. Similarly, the Library could now allow selfrenewal of overdue books via OPAC for some user groups. A possible change for the future, if Aleph can be configured, would be to alter the system of recalls so that DL students' copies would be recalled last.

In an effort to create a "one-stop-shop" for distance learners, it was recommended that a dedicated email address and phone number were assigned to Distance Learning Library Services. Again, this would not cost the Library much, but would make all the difference to a distance learner.

\section{One-off web improvements}

Perhaps the largest list of recommendations fell under the heading "one-off webbased improvements". Of course, a small percentage of our DL students will not have access to the web. However, those that do will expect to get maximum benefit from web-based library services. Indeed it is frequently asserted in the literature that a library's web pages are the library to a distance learner (Linden, 2000, and Fletcher, 2000). It was recommended therefore, that the Distance Learning web pages should have a direct link from the Library Home Page and a memorable URL. A link should also be provided from the Library Home page and Distance Learning page to relevant Computing Services web pages. In terms of additional content, the Group suggested:

- A series of links to tables of contents of books and book reviews;

- A collection of web-based reference material;

- A list of public and professional institution libraries with contact details and opening hours:

- A list of commercially run copy shops. (Sponsorship for this activity could be considered);

- A list of stationery suppliers (e.g. Staples). (Sponsorship for this activity could be considered).

Improvements were suggested for the A-Z list of databases too. To ensure that remotely accessible e-resources were easily identifiable, the group suggested an "at-aglance” icon marking out such resources. It was also suggested that usernames and passwords were made available on the University's Virtual Learning Environment so that it could be accessible remotely by legitimate users. A link to the Electronic Enquiry Service should also be created on the Electronic Resources page whereby distance learners can apply for usernames and passwords.

\section{Added value services}

The Group appreciated that some services could only be provided at a fee, not only to offset some of the cost of providing them, but also to limit demand. Having said that, the Group recommended that the cost of the existing books-by-post and photocopying service were reduced in line with other HEIs. The only new transaction-based service they recommended was literature searching, to be carried out either by the Distance Learning Librarian, should one be appointed (see below), or the relevant Academic Librarian. This would enable distance learners to benefit from the same range of databases and abstracts as on-campus students. The recommended fee was $£ 5$ per source.

\section{Investment services}


The final range of service improvements could not be provided on a transaction basis, nor could they be provided within the library's existing budget. These were classed as investment services, referring to the need for the University to invest funding in them if they were to succeed. The main university-wide change that the Library was recommended to lobby for was the unique identification of distance learners on the student administration database. This would allow the Library to easily and equitably differentiate its services. The Group also recommended that the Library apply for funding for an additional 0.5 Distance Learning Librarian post to provide practical services and personal assistance to distance learners such as book fetching, literature searching, a help-line, web pages, and so on. Failing this, funding for a 0.5 Project Officer for six months would greatly facilitate the establishment of new systems for DL students. These would include web-based forms for the photocopying service, the updating of the DL web pages, and so on.

One recommendation that emanated from every stage of the Group's analysis was increased vacation opening hours. A staged increase in opening hours was suggested: in the short term, the Library could open on a Monday evening until 8pm and/or on Saturday, during the Christmas and Easter vacations. In the long term, it was recommended that the Library extend its term time hours into the Easter and Christmas vacations, and open on a Monday evening until 8pm and a Saturday during the Summer vacation. This, again, would depend on additional funding from the University. Indeed it has been calculated that the long-term extension of opening hours would add $1 \%$ to the annual library expenditure.

\section{Significant new services}

Five recommendations represented significant new projects or services that could again only be provided with the investment of additional funds. The first of these was a copyright clearance service. This would not only allow the Library to digitise copyright materials for access by students, but would facilitate departments' own DL teaching activities too.

One major disparity between the library benefits to on- and off-campus students' was the ability to browse the shelves. As one of our DL survey respondents pointed out, books-by-post is a very expensive way to browse! One solution offered by the Group was to include tables of contents and book reviews either on the OPAC itself, or at least a set of links to web sites providing this information (see above). This would allow students the ability to make informed choices about their loans. However, Loughborough University theses would not be covered by this solution and because they were reference only could not be "browsed" by post. It was therefore suggested that abstracts of local theses should be provided either on OPAC or on a separate web-based database.

The Group also recommended another database, namely, a database of all electronic resources (past, present and trials) should be created. This should pool all the information currently kept in separate spreadsheets such as cost, usage, renewal date, "wish list" resources, and so on. In particular, it should contain licence terms as they relate to remote access and document delivery. (Some databases will allow remote access on a case-by-case basis on application). This would aid Library staff to provide access information to distance learners. 
Two other services requiring significant additional funds were a virtual Self-Guided Tour of the Library to allow DL students to plan their visit in advance, and a computer-aided learning IST package to meet the information skills needs of those studying at a distance.

\section{Conclusions}

Implementing and maintaining service improvements for DL students is undoubtedly more efficient with additional staff resources. The danger of being seen to be doing "something for nothing" is that bids for additional funding may fall on deaf ears. It should not be considered unreasonable to seek additional funds to provide an equitable library service to distance learners. As the Follett Report famously asserts, "our students are our responsibility" (Bye, 1999; JISC, 1993). However, the Group discovered that in many cases it was possible to enhance library services for a diverse DL student population without additional funding.

\section{References}

Association of College and Research (1998). ACRL guidelines for distance learning library services: Libraries. URL: http://www/ala/org/acrl/guides/distlrng.html (Accessed 22 March 2001)

Burch, M. (1999). Funding library services for distance learners: "what's the problem?" In D. A. Lock (Ed.), Library services for distance learners: proceedings of the seminar at University of Surrey, 13 January 1999.: 23-31. Surrey: Information Services : University of Surrey.

Bye, D. J. (1999). The distance learner support service: Sheffield Hallam University. In D. A. Lock (Ed.), Library services for distance learners: proceedings of the seminar at University of Surrey, 13 January 1999.: 9-12. Surrey: Information Services :

University of Surrey.

Cervone, F., and Brown, Doris. (2000). Transforming library services to support distance learning: strategies used by the DePaul University Libraries. College and Research Libraries News, February: 147-149.

Fletcher, J. (2000). Designing the library home page for distance education learners. In P. Brophy, Fisher, Sheila, and Clarke, Zoe (Ed.), Libraries without walls 3: the delivery of library services to distant users: proceedings of an international conference held on 10-14 September 1999, organized by the Centre for Research in Library and Information Management (CERLIM), Manchester Metropolitan University: 60-77. London: Library Association.

Gibson, A., Newton, R., and Dixon, D. (1999). Supporting open and distance learners: practice and policy across further and higher education libraries. Library Review, 48(5): 219-231.

Joint Information Systems Committee (JISC). (1993). Joint Funding Council's Libraries Review Group: Report (The Follett Report). Bristol: JISC. URL: http://www.ukoln.ac.uk/services/papers/follett/report/ (Accessed 21 December 2001) 
Leicester University Library. Distance Learning Unit. URL:

http://www.le.ac.uk/li/distance/index.htm (Accessed 17 December 2001)

Linden, J. (2000). The library's web site is the library: designing for distance learners. College and Research Libraries News, February: 99-101.

Open University. Online Personal Academic Librarian (OPAL) Project. URL: http://oulib1.open.ac.uk/wh/research/opal/. (Accessed 19 December 2001)

Raven, D. (1999). Breaking the campus boundary. The Library Association Record, 101(6): 346-348.

SCONUL. (2001). SCONUL Task Force on Access for Distance Learners. London: SCONUL.

Sheffield Hallam University. Distance Learner Support Service. URL: http://www.shu.ac.uk/services/lc/dl/index.html (Accessed 17 December 2001)

UK Libraries Plus, URL: http://www.roehampton.ac.uk/uklibrariesplus/index.html (Accessed 17 December 2001)

University of Surrey. Distance Learners' Information Service (DILIS). URL: http://www.surrey.ac.uk/Library/dilis/index.htm (Accessed 17 December 2001)

Wolpert, A. (1998). Services to remote users: marketing the library's role. Library Trends, 47(1): 21-41. 